\title{
Numerical analysis of the performance of green façades
}

\author{
Frédéric Poupart Oda Martine Sundsdal Marianne Christiansen Ole Melhus Arnab Chaudhuri \\ Department of Civil Engineering and Energy Technology \\ OsloMet - Oslo Metropolitan University, Oslo, Norway. \\ frederic.poupart@hotmail.com, oda-martine@hotmail.com, mchrist@hotmail.no, \\ ole.melhuseoslomet.no, arnab.chaudhurieoslomet.no
}

\begin{abstract}
This study reports a numerical analysis of the performance of green façades in different geographical locations and seasonal conditions. A mathematical model from a previous study is implemented and combined with the modified convective heat transfer coefficients from a recent study of the literature to simulate the transient heat transfer through bare walls and green facades with climbing vegetation. An implicit Finite Difference Method (FDM) based solver is used to perform the numerical simulations. Climate data are taken from relevant weather stations in Oslo and Rome and typical meteorological year (TMY) values are used for this purpose together with variable thermo-physical properties of air. An energy budget analysis reveals that the short-wave radiation term and convective heat transfer term are predominating compared to the other terms involved in the energy balance equation for summer time. The results show that the green walls are most effective in summer seasons with high levels of solar radiation, as most of the cooling effect is credited to the vegetation blocking the solar radiation. In cooler seasons, the benefit is less prominent. Furthermore, an analysis of the effects of the different models of convective heat transfer coefficients is presented.
\end{abstract}

Keywords: green buildings, green vertical systems, green façades, passive design, sustainability

\section{Introduction}

Recent studies show a drastic increase of global energy use over the last four decades. Based on the United Nations report and as mentioned by several authors, it is estimated that the population in cities will increase up-to $68 \%$ by 2050 (UN, 2018; Vo et al., 2019; Seyam, 2019; Besir and Cuce, 2018) with urban dwellers reaching $\approx 6.7$ billion. In this regard, the building sector accounts for a large portion of the total energy usage, as well as $36 \%$ of the total greenhouse gas emissions is attributed to the building sectors (Vo et al., 2019; Seyam, 2019). For this, the United Nations Environment Program (UNEP) proposes several measures like increasing the energy efficiency of buildings, appliances, reduction of emission, approach towards energy usage and promoting technologies with renewable energies rather than fossil fuels.

Integrating plants into the building envelope addresses both aesthetic and energy concerns. Utilizing different types of greenery systems, microclimatic conditions of buildings can be more cost-effective and eco-friendlier (Seyam, 2019; Koc et al., 2018; Besir and Cuce, 2018). Green buildings with green infrastructures like green horizontal systems and green vertical systems are sustainable, efficient and passive design solutions for effects associated with rapid urbanization, addressing issues with a high carbon footprint, high greenhouse gas emission, urban heat island effects etc. (Susca et al., 2011; Safikhani et al., 2014; Manso and Castro-Gomes, 2015; Charoenkit and Yiemwattana, 2016; Koc et al., 2018). Green roofs (GR) and vertical greenery systems like green façades(GF)/living walls differ fundamentally due to the structure of the assembly and differences in the involved heat transfer processes (Susorova et al., 2013; Pérez et al., 2014; Bustami et al., 2018). A detailed classification of green walls based on the construction characteristics is presented by (Manso and Castro-Gomes, 2015). Scientific studies established the energy saving benefits of green infrastructures in building sectors (Feng and Hewage, 2014; Raji et al., 2015). It is also a proven fact that the presence of green systems has an important psychological impact on urban dwellers. Thermal insulation, shading effects, evapotranspiration and wind effects are the key features towards the energy saving impacts of greenery systems. Several parameters like substrate thickness, soil moisture, solar radiation inception, density of foliage and the coverage, ventilation blind effects, thickness of the foliage, air layer, orientation, wind barrier/blockage etc. are to be accounted for in mathematical modeling of such systems. Plant characteristics, weather conditions, climate zones, wall assembly types, façade orientations etc. are to be considered in modeling and analysis of thermal benefits.

In this regard, Alexandri and Jones developed a dynamic one dimensional model for green roof accounting the fundamental heat and mass transfer mechanisms (Alexandri and Jones, 2007) involved in the energy dynamics. On the other hand, a quasi steady state approach was adopted by (Tabares-Velasco and Srebric, 2012) in their green roof model. Further developments on the green roof model are reported in (Heidarinejad and Esmaili, 2015; He et al., 2017). For vertical greenery systems, a mathematical model of building exterior wall with climbing vegetation is presented in (Susorova et al., 2013). Sev- 
eral other authors considered the heat balance of the foliage and heat transfer through the substrate layer of the vertical greenery system and integrated models in building simulation programs like TRNSYS and EnergyPlus (Djedjig et al., 2015, 2017; Dahanayake and Chow, 2017). A multilayered model approach for vegetated vertical systems is presented in (Convertino et al., 2019a). Nevertheless, studies on the modeling aspects of green roof/green façades are still an active field of research and development.

In this work, we have revisited the model proposed in (Susorova et al., 2013). We aim to implement this green façade model combining the effects of the modified convective heat transfer coefficients presented in the recent work of (Convertino et al., 2019b). The main objective of this work is to investigate the applicability of the aforementioned model and to analyze the performance of the green wall envelope of buildings, for different climate data revealing the possible benefit of employing green façades in buildings. The paper is organized as follows. In section 2 , we present the governing equations and the numerical methodology of the study together with the problem setup. The detailed analysis of the results is given in section 3 . Finally, the conclusions are drawn in section 4.

\section{Method}

\subsection{Governing equation}

The green façade model of Susorova et al. accounts the various heat transfer mechanisms for a vegetated wall $(\mathrm{Su}-$ sorova et al., 2013), and the energy balance is defined as:

$$
S R_{v w}+L R_{v w}+X R+C_{v w}=Q_{v w}+S_{v w}
$$

Where $S R_{v w}$ is the incident shortwave radiation, $L R_{v w}$ is the net long-wave radiation, $X R$ is the radiative exchange between the leaves and wall surface, $C_{v w}$ is the convective heat flux, $Q_{v w}$ is the conduction heat flux and the heat storage in the façade material is $S_{v w}=\rho C_{p} L\left(d T_{v w} / d t\right)$, with density of the wall material $\rho$, specific heat of the wall $C_{p}$, wall thickness $L, t$ is the time and $T_{v w}$ is the wall temperature. A schematic of the energy balance and a very brief description of the terms of the Equation 1 are given in Appendix A for the sake of completeness and to facilitate the understanding of the overview of the mathematical model. Details of the model can be found in (Susorova et al., 2013). Note that essentially, the wall temperature $T_{v w}(t)$ is linked with the air temperature $T_{\text {air }}(t)$, the sky temperature $T_{s k y}(t)$, the ground temperature $T_{g r}(t)$, the indoor air temperature $T_{i n}(t)$ and the leaf temperature $T_{\text {leaf }}(t)$. The energy balance equation of bare wall is similar to equation 1 , without the $X R$ term and the unknown bare wall temperature denoted as $T_{b w}$. The energy balance equation is therefore expressed as:

$$
S R_{b w}+L R_{b w}+C_{b w}=Q_{b w}+S_{b w}
$$

The governing ordinary differential equations (ODEs) can be expressed in the following form:

$$
\begin{aligned}
& \frac{d T_{v w}}{d t}=a_{v w}(t)+b_{v w}(t) T_{v w}+c_{v w}(t) T_{v w}^{4} \\
& \frac{d T_{b w}}{d t}=a_{b w}(t)+b_{b w}(t) T_{b w}+c_{b w}(t) T_{b w}^{4}
\end{aligned}
$$

Where, the time varying coefficients $\left(a_{v w}, b_{v w}, c_{v w}, a_{b w}\right.$, $b_{b w}$ and $c_{b w}$ ) are functions of the other associated temperatures and the relevant thermo-physical properties.

\subsection{Numerical procedure}

The implicit form of the discretized equations for the ODEs can be given by,

$$
\begin{aligned}
& \frac{T_{v w}^{n+1}-T_{v w}^{n}}{\Delta t}=a_{v w}^{n+1}+b_{v w}^{n+1} T_{v w}^{n+1}+c_{v w}^{n+1}\left(T_{v w}^{n+1}\right)^{4} \\
& \frac{T_{b w}^{n+1}-T_{b w}^{n}}{\Delta t}=a_{b w}^{n+1}+b_{b w}^{n+1} T_{b w}^{n+1}+c_{b w}^{n+1}\left(T_{b w}^{n+1}\right)^{4}
\end{aligned}
$$

Where, $\Delta t$ is the time step and the superscripts $n$ and $n+1$ denotes the time levels of the discretization.

The implicit FDM based solver is developed using Matlab programming language to compute the transient temperature of the wall with a time step of one minute.

\subsection{Problem setup}

Simulations are performed in which the temperature of the façade is computed over a 24 -hour period. To perform these computations, hourly weather data is gathered through the EU's photovoltaic geographical information system and a local weather station in the relevant cities (Norsk klimaservicesenter, 2020; The European Commission's science and knowledge service, 2019; YAGA AS, 2020). A suitable interpolation procedure is adopted to produce weather data for a time resolution in minutes. The green façade is assumed to be consisted of a brick wall covered with Boston Ivy and the corresponding relevant material properties are used. Among the necessary parameters, $\rho, C_{p}, L$ and $T_{i n}$ are assumed to be $672 \mathrm{~kg} / \mathrm{m}^{3}$, $468 \mathrm{~J} / \mathrm{kgK}, 0.2 \mathrm{~m}$ and $295 \mathrm{~K}$ respectively. The choice of $T_{\text {in }}$ is based on the recommended operating temperature mentioned in Norwegian standard (TEK17, 2017). All other parameters used in the simulations are summarized in Appendix A. Two seasons (summer and winter) are considered for the performance behavior of the mathematical model in the geographical location of the cities Rome and Oslo. Note that an initial temperature of the wall is required to achieve the time marching solutions. To avoid this initial data affecting the results, simulations are performed over a 48 hour period, of which the last 24 hours are extracted as the result. In the next section, we present the results of the simulations for different scenarios.

\section{Results and Discussions}

In this section, we first illustrate the relative importance of the individual terms of the energy balance equation. This 
is followed by the comparison of the performance of the green façades in different scenarios. Finally, the analysis of the impact of the convective heat transfer coefficient with various empirical models is presented at the end.

\subsection{Energy budget}

The budget of the terms of the energy equation for bare walls and green walls are calculated after finding the wall temperatures. For this analysis, a typical summer day situation in Oslo region is considered. The contributions of each term in the energy equation are shown in Figure 1 and Figure 2 for a bare wall and green wall, respectively. It is clear from these figures that the contributions from the convection term and the solar short-wave radiation term are dominant from 09:00 hrs to 19:00 hrs for both the walls. For example, at 14:00 hrs the contribution of the short-wave radiation term $S R_{v w}$, and convection term $C_{v w}$ for the green wall are $\approx 49 \%$ and $\approx 40 \%$ respectively. On the other hand, for bare wall the contribution of $S R_{b w}$ and $C_{b w}$ are found to be $\approx 50 \%$ and $\approx 37 \%$. It can be noticed that the values of all budget terms are significantly reduced in the green wall essentially due to the blockage of the radiation and associated lower temperature differences. The contribution of the radiative exchange term $X R$, for the green wall is found to be relatively less compared to the other terms.

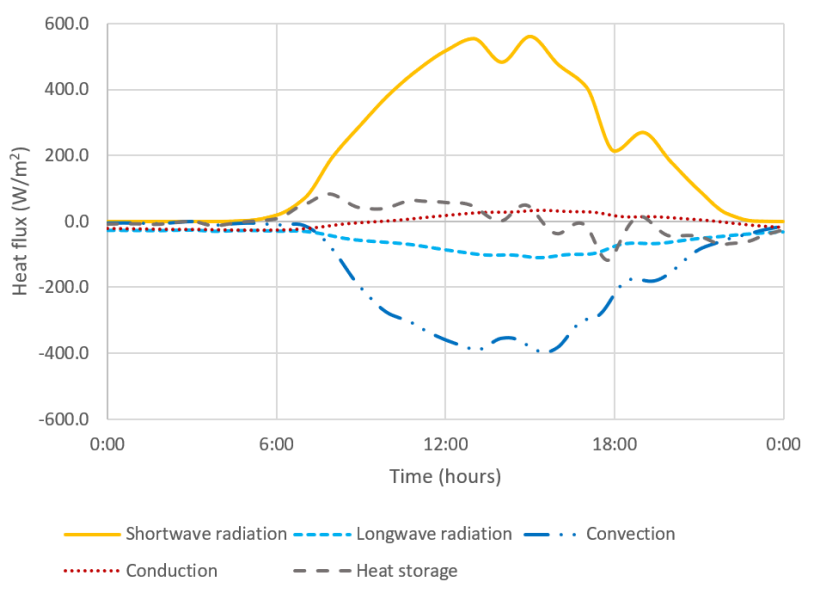

Figure 1. Energy budget bare wall.

\subsection{Performance of green façades in different climates and seasons}

Here we present the results of the performance of the bare wall and the green wall in two different locations in Europe namely Rome and Oslo using the weather data for the month of July and February 2019.

Figure 3 shows the comparison between the bare wall and green wall temperature in summer situation for both cities. Evidently, green wall reduces the wall temperature and thereby is capable of reducing the cooling demand in peak hours in daytime (6:00 hrs to 18:00 hrs for Rome and 7:00 hrs to $22 \mathrm{hrs}$ in Oslo). This clearly depicts the

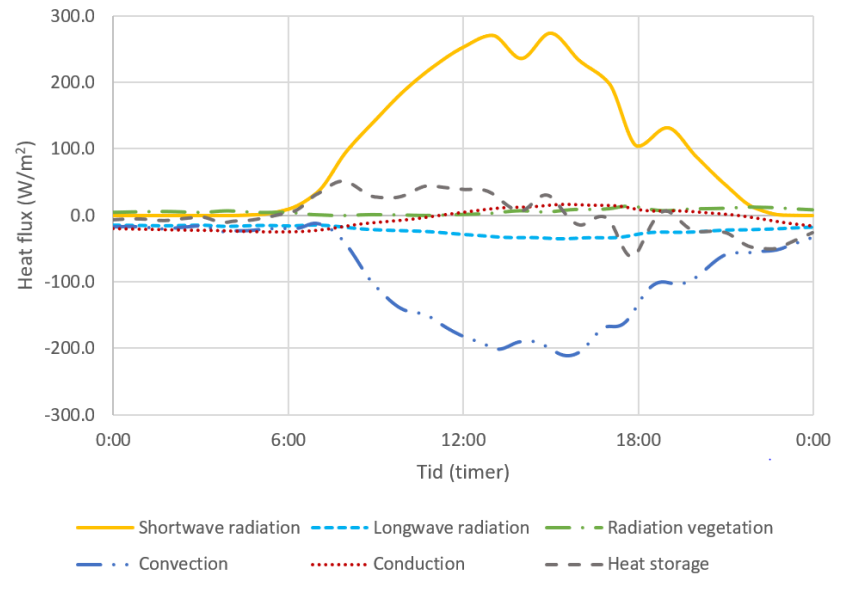

Figure 2. Energy budget green wall.

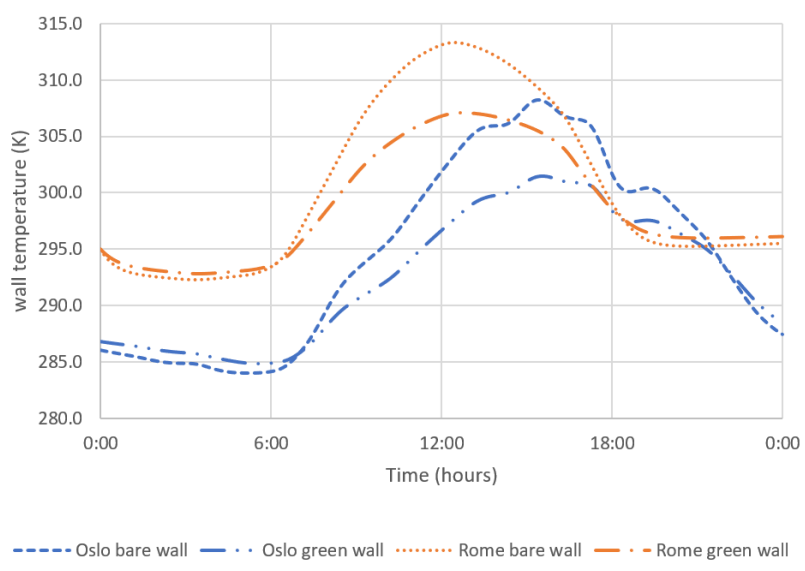

Figure 3. Wall temperature of bare- and green walls over a summer day in Rome and Oslo.

effectiveness of the green vegetation countering with the dominant incident radiation component.

It can be realized that a temperature drop of about $6-7 K$ (see Figure 4 ) is achievable with the application of green vegetation in the summer daytime. Also, the cooling effect lasts relatively longer in Oslo $(\approx 3 \mathrm{hrs}$ more $)$ than Rome. This is directly linked with relatively longer daytime in Oslo than Rome in the month of July. Note that, an estimate of the reduction of cooling demand can be made from the conductive heat flux term of the energy balance equation. This cooling demand reduction on an average is found to be $\approx 10 \mathrm{~W} / \mathrm{m}^{2}$ for Rome and $\approx 9 \mathrm{~W} / \mathrm{m}^{2}$ for Oslo. In nighttime, the green wall temperatures are found to be marginally higher than the bare walls in both the cities and the green layer reduces the heat loss due to long-wave radiation.

The results of the simulations in winter scenarios for Rome and Oslo are shown in Figure 5 in terms of wall temperature for both the bare wall and the green wall. In Rome during the daytime, 8:00 hrs to 15:00 hrs a maximum drop of about $2-3 K$ (see the temperature difference between the bare wall and the green wall Figure 6) is ob- 


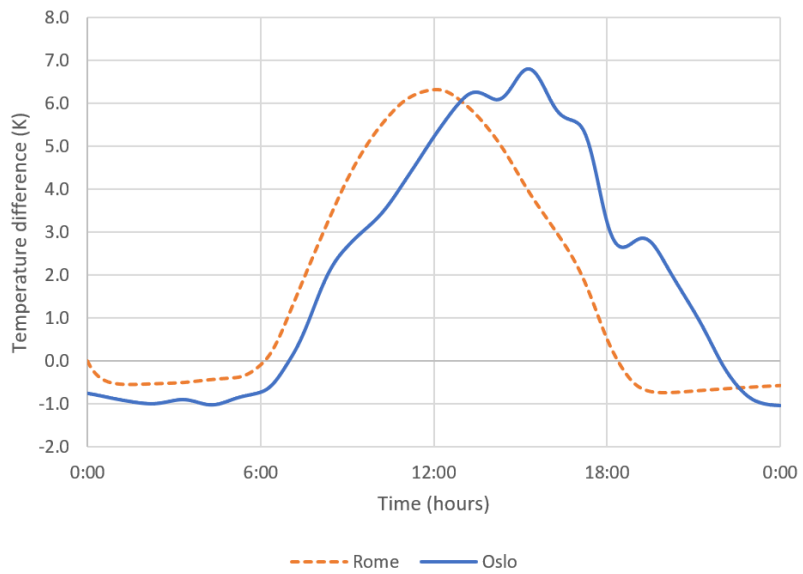

Figure 4. Temperature difference between bare- and green walls over a summer day in Rome and Oslo.

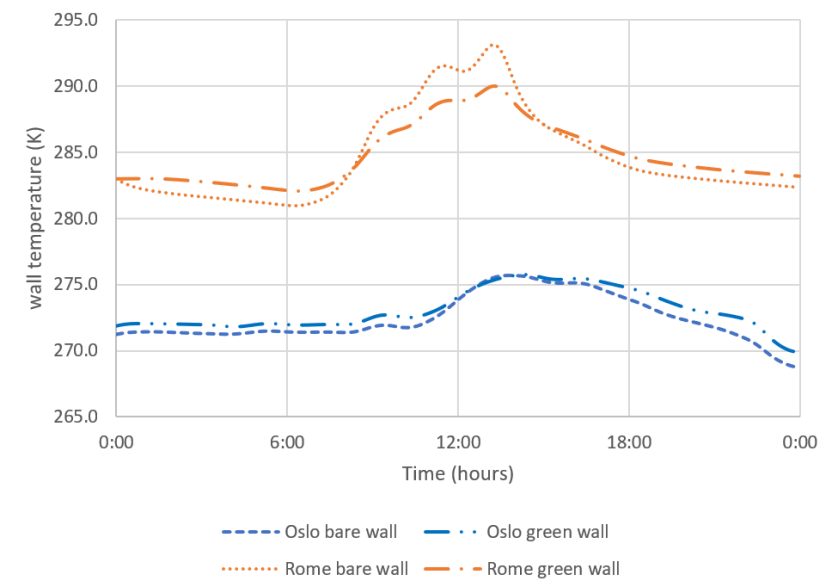

Figure 5. Wall temperature of bare- and green walls in Rome and Oslo, Winter.

served. This leads a marginal increase in heating load during this time. The rest of the day and nighttime the wall temperature remains about $1 K$ higher for the green wall. However, in Oslo climate, the winter is much more severe compared to Rome. The green wall temperature remains $\approx 1 K$ higher most of the time, except a very short period of the daytime. This provides very marginal benefits on heating demand in places having colder climate.

\subsection{Impact of convective heat transfer coeffi- cient}

The analysis presented in the previous sections 3.1 and 3.2 , are completely based on the mathematical model of Susorova et al. (Susorova et al., 2013). The energy budget analysis in section 3.1 reveals that the convective heat flux term is one of the important contributors in the energy balance equation. The convective heat transfer coefficient for green wall in the energy balance model (Susorova et al., 2013) is approximated with the same correlation as for bare wall case $\left(h_{v w} \approx h_{b w}=10.79+4.192 V\right.$, where $V$ is the air speed at the bare façade). In this work, we intend to

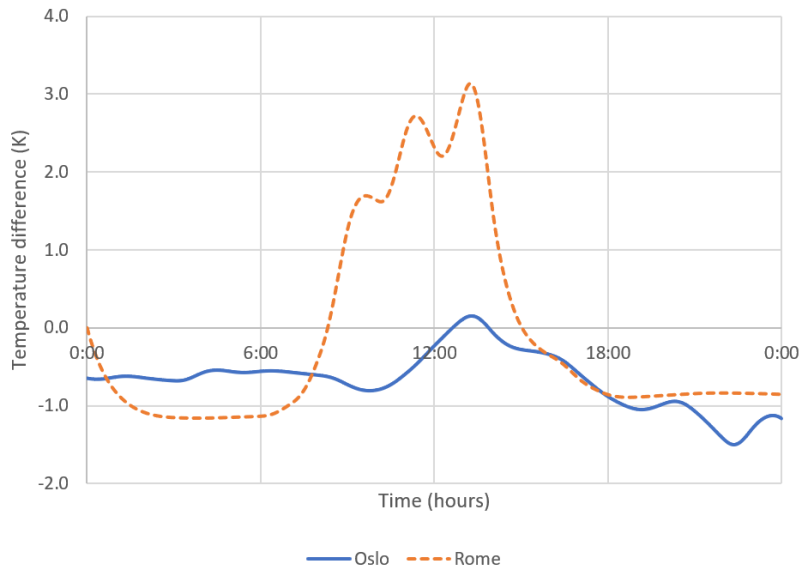

Figure 6. Temperature difference between bare- and green walls over a summer day in Rome and Oslo.

explore the other relevant correlations (Deardorff, 1978; Stanghellini, 1987; Morrison Jr and Barfield, 1981; Ayata et al., 2011; Campbell and Norman, 2012; ASHRAE, 2020 ) as mentioned in the recent work of Convertino et al. (Convertino et al., 2019b). The expressions of convective heat transfer coefficients are summarized in Appendix B.

A typical summer scenario in the Oslo climate region is considered for this analysis. Figure 7 shows the wall temperature of the green wall for various $h_{v w}$ values as mentioned before. Based on the input weather data, thermophysical properties and plant characteristics we found that the Richardson number $R i<10^{-2}$ throughout the day. This implies that the convection type can be considered as forced convection. The application of mixed regime Nusselt number $N u$, following (Stanghellini, 1987) is therefore omitted for comparison in this analysis. Note that, increase in $h_{v w}$ leads to decrease in wall temperature comparatively.

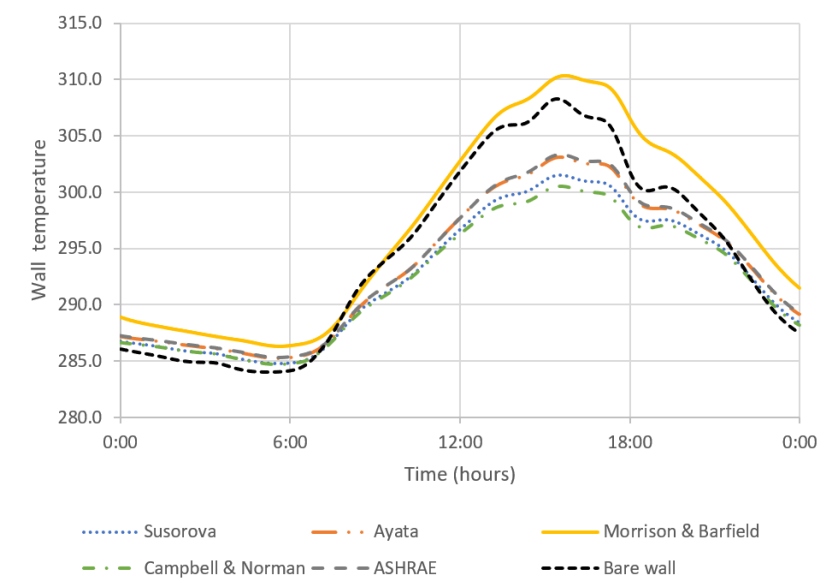

Figure 7. Calculated wall temperature with different approaches of finding the heat transfer coefficient.

It can be seen from Figure 7 that (Campbell and Norman, 2012) approach yields lower wall temperature than that of (Susorova et al., 2013). On the other hand, higher 
wall temperatures are obtained by (Ayata et al., 2011; ASHRAE, 2020; Morrison Jr and Barfield, 1981) methods. Among these, (Ayata et al., 2011; ASHRAE, 2020) methods yield almost identical result as they are both based on McAdams' equation. On the other hand, (Morrison Jr and Barfield, 1981) approach gives far lower values for the convection coefficient and therefore much higher wall temperature (even higher than the bare wall) is estimated. It is clear that, there is a wide variation in the prediction of green wall temperature when applying the different methods of calculating the convective heat transfer coefficient compared to Susorova's model. As mentioned in (Susorova et al., 2013), some studies showed a decrease in values of convective heat transfer coefficients for a wide range of vegetated façade types, the present findings through the (Ayata et al., 2011; ASHRAE, 2020) methods are in accordance with this trend. It is known that the building geometry, surroundings and wind directions have a significant effect on the magnitude of the convective heat transfer coefficient (Defraeye et al., 2011; Iousef et al., 2019). Several correlations are based on the results of flat plate experiments in wind tunnels (Jayamaha et al., 1996) and may not fully capture the local variations of geometry and wind directions around the building façades.

\section{Conclusions}

Modeling aspects of green roof/green façades require to deal with complex interactions associated with plants, soils, building materials, surrounding atmosphere and solar radiation. This fundamentally involves transient coupled heat and mass transfer mechanisms. In this work, we have revisited the mathematical model of building exterior wall with climbing vegetation as presented in (Susorova et al., 2013). An implicit FDM based solver is developed to perform simulations for two different seasons in Oslo and Rome and typical meteorological year (TMY) values are used together with variable thermo-physical properties of air.

An energy budget analysis reveals that the short-wave radiation term and convective heat transfer term are predominating compared to other terms involved in the energy balance equation for summer time. The performance of green wall showed capability of decreasing the cooling demand in summer time quite significantly for both Rome and Oslo. With recent trends in climate change, the cooling need in the Oslo area will most likely increase in the next few years. During the winter, however, the decrease in heating demand is not as significant as the reduced cooling demand noticed in summer time. Nevertheless, especially in relatively cold winter regions like Oslo, the green wall still helps to increase the wall temperature compared to the bare wall. Furthermore, we have analyzed several different methods for the estimation of the convective heat transfer coefficient as the convective term in the energy balance equation plays an important role opposing the solar radiation gain. The prediction of the behavior of the wall temperatures for green wall with methods in previous literatures are in accordance with the expected trend. Nevertheless, further detailed studies with supporting experimental data, the limitations of this simplified green façade model can be improved. The detailed analysis of the longwave radiation term, radiative exchange term between the leaves and the wall surface will be undertaken in our future work.

\section{Appendix A}

In this section, we present a brief description of the mathematical model (see details in (Susorova et al., 2013)) and the input parameters used in the simulations. Figure 8 illustrates the schematic view of the green wall setup and associated energy transfer processes.

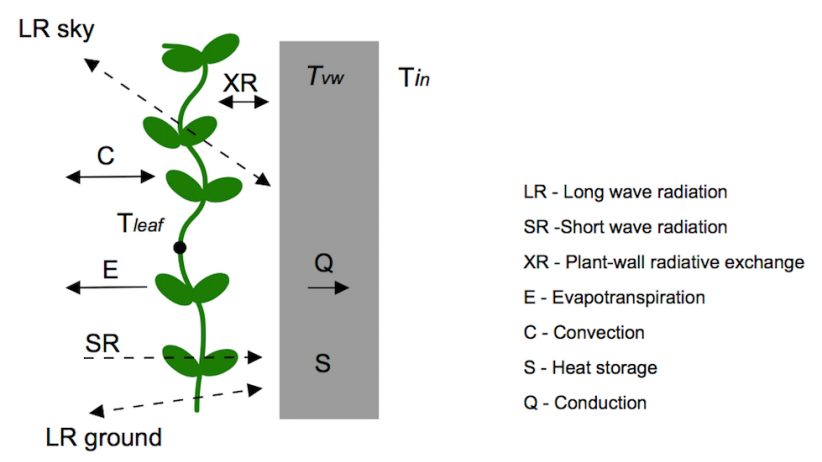

Figure 8. Schematic of the energy balance of the green wall (Susorova et al., 2013; Vo et al., 2019).

The terms of the equation 1 for green wall are given by,

$$
\begin{aligned}
S R_{v w} & =I_{t} \alpha_{w} \tau \\
L R_{v w} & =\tau \varepsilon_{w} \varepsilon_{s k y} \sigma F_{\text {sky }}\left(T_{s k y}^{4}-T_{v w}^{4}\right)+\tau \varepsilon_{w} \varepsilon_{g r} \sigma F_{g r}\left(T_{g r}^{4}-T_{v w}^{4}\right) \\
X R & =(1-\tau) \frac{\varepsilon_{w} \varepsilon_{\text {leaf }} \sigma}{\varepsilon_{w}+\varepsilon_{\text {leaf }}-\varepsilon_{w} \varepsilon_{\text {leaf }}}\left(T_{v w}^{4}-T_{\text {leaf }}^{4}\right) \\
C_{v w} & =h_{v w}\left(T_{\text {air }}-T_{v w}\right) \\
Q_{v w} & =\left(T_{v w}-T_{\text {in }}\right) / R_{b w} \\
S_{v w} & =\rho C p L\left(d T_{v w} / d t\right)
\end{aligned}
$$

On the other hand, the terms of the equation 2 for bare wall are given by,

$$
\begin{aligned}
S R_{b w} & =I_{t} \alpha_{w} \\
L R_{b w} & =\varepsilon_{w} \varepsilon_{s k y} \sigma F_{s k y}\left(T_{s k y}^{4}-T_{b w}^{4}\right)+\varepsilon_{w} \varepsilon_{g r} \sigma F_{g r}\left(T_{g r}^{4}-T_{b w}^{4}\right) \\
C_{b w} & =h_{b w}\left(T_{a i r}-T_{b w}\right) \\
Q_{b w} & =\left(T_{b w}-T_{i n}\right) / R_{b w} \\
S_{b w} & =\rho C p L\left(d T_{b w} / d t\right)
\end{aligned}
$$

Where $I_{t}$ is the total solar radiation incident on the wall, $\alpha_{w}$ is the wall absorptivity, $\tau$ is the plant layer transmissivity of radiation, $\varepsilon_{w}, \varepsilon_{s k y}, \varepsilon_{g r}$ and 
$\varepsilon_{\text {leaf }}$ are the emissivities of the wall, sky, ground and plant layer, respectively. The values are assumed as $\alpha_{w}=0.7, \varepsilon_{w}=0.9, \varepsilon_{\text {sky }}=1, \varepsilon_{g r}=0.9, \varepsilon_{\text {leaf }}=0.96$. The plant layer transmissivity, $\tau=\exp (-\kappa L A I)$. Here, the radiation attenuation coefficient $\kappa$ (taken as $0.4 \mathrm{~W} / \mathrm{mK}$ ), and the leaf area index $L A I$ (assumed as 1.8). $\sigma$ is the Stefan-Boltzmann constant. $F_{s k y}$ and $F_{g r}$ are the view factors between the wall, sky and ground, $T_{s k y}$ is the temperature of the sky, $T_{v w}$ is the temperature of the vegetated wall, $T_{b w}$ is the temperature of the bare wall, $T_{g r}$ is the temperature of the ground (assumed equal to $\left.T_{\text {air }}\right), T_{\text {leaf }}$ is the leaf temperature, $h_{v w}$ and $h_{b w}$ are the convection heat transfer coefficient of the vegetated and bare wall (see Appendix B).

$T_{s k y}$ is calculated as a function of the air temperature and dewpoint temperature as:

$$
T_{\text {sky }}=T_{\text {air }}\left(0.8+\frac{T_{\text {dew }}-273}{250}\right)^{0.25}
$$

The view factors are calculated as a function of the tilt angle $\theta$

$$
\begin{aligned}
F_{g r} & =0.5(1-\cos \theta) \\
F_{s k y} & =0.5(1+\cos \theta)
\end{aligned}
$$

For the vertical greenery systems the tilt angle is equal to $90^{\circ}$, resulting in both view factors equal to 0.5 .

The equation for calculating $T_{\text {leaf }}$ can be found in (Susorova et al., 2013). The necessary parameters are the thermodynamic phsycrometer constant $\gamma\left(0.000666^{\circ} \mathrm{C}^{-1}\right)$, radiative conductance through air $g_{r}$ (obtained through table A3 in (Campbell and Norman, 2012)), the leaf characteristic dimension $D(0.12 \mathrm{~m})$, typical stomatal conductance of lower and upper leaf surface $g_{s l l}$ and $g_{s u l}$ $\left(0.2 \mathrm{~mol} / \mathrm{m}^{2} \mathrm{~s}\right)$, leaf absorptivity $\alpha_{\text {leaf }}(0.5)$, relative humidity of the air $R H$, specific heat of the air $C_{\text {pair }}$ $(29.3 \mathrm{~J} / \mathrm{molK})$, air pressure $P_{\text {air }}$.

\section{Appendix B}

The various models for convective heat transfer coefficients used in the simulations and mentioned in section 3.3 are presented below.

Susorova uses the following equation:

$$
h_{v w}=a+b V+c V^{2}
$$

Where $V$ is the wind speed and $a, b$ and $c$ are coefficients based on the material roughness. The wall surface is assumed to be of medium roughness, with the coefficients equal to $10.79,4.192$ and 0 , respectively.

Morrison \& Barfield and Stanghellini calculate $h_{v w}$ based on the Nusselt number, which is given in equations $\mathrm{B} 3$ and $\mathrm{B} 4$ respectively.

$$
\begin{gathered}
h_{v w}=\frac{N u \lambda}{D} \\
N u=0.328 \operatorname{Pr}^{0.33} R^{0.5} \\
N u=0.37\left(G r+6.92 R e^{0.5}\right)
\end{gathered}
$$

Where $N u$ is the Nusselt number, $R e=\frac{D V}{v}$ is the Reynolds number, $G r=\frac{g \beta D^{3}}{v^{2}}\left(T_{\text {air }}-T_{\text {leaf }}\right)$ is the Grashof number. $\lambda$ is the air thermal conductivity, $P r$ is the Prandtl number, $g$ is the gravitational acceleration constant $\left(9.81 \mathrm{~m} / \mathrm{s}^{2}\right), \beta$ is the thermal expansion coefficient of air $\left(0.0034 K^{-1}\right)$, and $v$ is the kinematic viscosity of air.

The Ayata and ASHRAE models calculate $h_{v w}$ on the basis of McAdams' equation and are presented in equations B5 and B6, respectively.

$$
\begin{gathered}
h_{v w}=5.9+4.1 V \frac{511+294}{511+T_{\text {air }}} \\
h_{v w}=5.6+4 V
\end{gathered}
$$

Equations B5 and B6 are applicable for $V<5 \mathrm{~m} / \mathrm{s}$, otherwise $h_{v w}$ is calculated from:

$$
h_{v w}=7.2 V^{0.78}
$$

Lastly, for Campbell \& Norman model, $h_{v w}$ utilizes the boundary layer conductance for heat transfer as:

$$
h_{v w}=g_{b h} C p_{a i r}
$$

where

$$
g_{b h}=1.4 \cdot 0.135 \sqrt{\frac{V}{D}}
$$

\section{References}

Eleftheria Alexandri and Phil Jones. Developing a onedimensional heat and mass transfer algorithm for describing the effect of green roofs on the built environment: Comparison with experimental results. Building and Environment, 42(8):2835-2849, 2007. doi:https://doi.org/10.1016/j.buildenv.2006.07.004.

ASHRAE. American society of heating, refrigerating, and air-conditioning engineers, 2020. URL https://www. ashrae.org/.

Tahir Ayata, Paulo Cesar Tabares-Velasco, and Jelena Srebric. An investigation of sensible heat fluxes at a green roof in a laboratory setup. Building and Environment, 46(9):1851-1861, 2011. doi:https://doi.org/10.1016/j.buildenv.2011.03.006.

Ahmet B Besir and Erdem Cuce. Green roofs and facades: A comprehensive review. Renewable and Sustainable Energy Reviews, 82:915-939, 2018. doi:https://doi.org/10.1016/j.rser.2017.09.106. 
Rosmina A Bustami, Martin Belusko, James Ward, and Simon Beecham. Vertical greenery systems: A systematic review of research trends. Building and Environment, 146:226-237, 2018.

Gaylon S Campbell and John Norman. An introduction to environmental biophysics. New York, USA, Springer Science \& Business Media, 2 edition, 2012.

Sasima Charoenkit and Suthat Yiemwattana. Living walls and their contribution to improved thermal comfort and carbon emission reduction: A review. Building and environment, 105:82-94, 2016. doi:https://doi.org/10.1016/j.buildenv.2016.05.031.

F Convertino, G Vox, and E Schettini. Heat transfer mechanisms in vertical green systems and energy balance equations. Urban Agriculture and City Sustainability, page 83, 2019a. doi:https:/doi.org/10.2495/DNE-V14-N1-7-18.

Fabiana Convertino, Giuliano Vox, and Evelia Schettini. Convective heat transfer in green façade system. Biosystems Engineering, 188:67-81, $2019 \mathrm{~b}$. doi:https://doi.org/10.1016/j.biosystemseng.2019.10.006.

KWD Kalani C Dahanayake and Cheuk Lun Chow. Studying the potential of energy saving through vertical greenery systems: Using energyplus simulation program. Energy and Buildings, 138:47-59, 2017.

James W Deardorff. Efficient prediction of ground surface temperature and moisture, with inclusion of a layer of vegetation. Journal of Geophysical Research: Oceans, 83(C4):18891903, 1978. doi:https://doi.org/10.1029/JC083iC04p01889.

Thijs Defraeye, Bert Blocken, and Jan Carmeliet. Convective heat transfer coefficients for exterior building surfaces: Existing correlations and cfd modelling. Energy Conversion and Management, 52(1):512-522, 2011. doi:https://doi.org/10.1016/j.enconman.2010.07.026.

R Djedjig, M El Ganaoui, Rafik Belarbi, and R Bennacer. Thermal effects of an innovative green wall on building energy performance. Mechanics \& Industry, 18(1):104, 2017.

Rabah Djedjig, Emmanuel Bozonnet, and Rafik Belarbi. Analysis of thermal effects of vegetated envelopes: Integration of a validated model in a building energy simulation program. Energy and buildings, 86:93-103, 2015.

$\mathrm{H}$ Feng and $\mathrm{K}$ Hewage. Energy saving performance of green vegetation on leed certified buildings. Energy and buildings, 75:281-289, 2014. doi:https://doi.org/10.1016/j.enbuild.2013.10.039.

Yang He, Hang Yu, Akihito Ozaki, Nannan Dong, and Shiling Zheng. Influence of plant and soil layer on energy balance and thermal performance of green roof system. Energy, 141: 1285-1299, 2017.

Ghassem Heidarinejad and Arash Esmaili. Numerical simulation of the dual effect of green roof thermal performance. Energy Conversion and Management, 106:1418-1425, 2015.
Samy Iousef, Hamid Montazeri, Bert Blocken, and Pieter van Wesemael. Impact of exterior convective heat transfer coefficient models on the energy demand prediction of buildings with different geometry. In Building Simulation, volume 12, pages 797-816. Springer, 2019. doi:https://doi.org/10.1007/s12273-019-0531-7.

SEG Jayamaha, NE Wijeysundera, and SK Chou. Measurement of the heat transfer coefficient for walls. Building and Environment, 31(5):399-407, 1996. doi:https://doi.org/10.1016/0360-1323(96)00014-5.

Carlos Bartesaghi Koc, Paul Osmond, and Alan Peters. Evaluating the cooling effects of green infrastructure: A systematic review of methods, indicators and data sources. Solar Energy, 166:486-508, 2018.

Maria Manso and João Castro-Gomes. Green wall systems: A review of their characteristics. Renewable and Sustainable Energy Reviews, 41:863-871, 2015. doi:https://doi.org/10.1016/j.rser.2014.07.203.

John E Morrison Jr and Billy J Barfield. Transpiring artificial leaves. Agricultural Meteorology, 24:227-236, 1981. doi:https://doi.org/10.1016/0002-1571(81)90047-9.

Norsk klimaservicesenter. Observasjoner og værstatistikk, 2020. URL https://klimaservicesenter.no/ observations/.

Gabriel Pérez, Julià Coma, Ingrid Martorell, and Luisa F Cabeza. Vertical greenery systems (VGS) for energy saving in buildings: A review. Renewable and Sustainable Energy Reviews, 39:139-165, 2014.

Babak Raji, Martin J Tenpierik, and Andy van den Dobbelsteen. The impact of greening systems on building energy performance: A literature review. Renewable and Sustainable Energy Reviews, 45:610-623, 2015. doi:https://doi.org/10.1016/j.rser.2015.02.011.

Tabassom Safikhani, Aminatuzuhariah Megat Abdullah, Dilshan Remaz Ossen, and Mohammad Baharvand. A review of energy characteristic of vertical greenery systems. $R e$ newable and Sustainable Energy Reviews, 40:450-462, 2014. doi:https://doi.org/10.1016/j.rser.2014.07.166.

Shaimaa Seyam. The impact of greenery systems on building energy: Systematic review. Journal of Building Engineering, page 100887, 2019.

Cecilia Stanghellini. Transpiration of greenhouse crops: an aid to climate management. 1987.

Tiziana Susca, Stuart R Gaffin, and GR Dell'Osso. Positive effects of vegetation: Urban heat island and green roofs. Environmental pollution, 159(8-9):2119-2126, 2011. doi:https://doi.org/10.1016/j.envpol.2011.03.007.

Irina Susorova, Melissa Angulo, Payam Bahrami, and Brent Stephens. A model of vegetated exterior facades for evaluation of wall thermal performance. Building and Environment, 67:1-13, 2013. doi:https://doi.org/10.1016/j.buildenv.2013.04.027. 
Paulo Cesar Tabares-Velasco and Jelena Srebric. A heat transfer model for assessment of plant based roofing systems in summer conditions. Building and Environment, 49:310-323, 2012.

TEK17. Direktoratet byggkvalitet, byggteknisk forskrift (TEK17) med veiledning, 2017. URL https://dibk.no/byggereglene/ byggteknisk-forskrift-tek17/.

The European Commission's science and knowledge service. Photovoltaic geographical information system, 2019. URL https://re.jrc.ec.europa.eu/pvg_ tools/en/tools.html\#TMY.

UN. 2018 revision of world urbanization prospects. Population Division of the UN Department of Economic and Social Affairs, 2018.

Trang Thuy Vo, Alexandru Nichersu, and Jochen Wendel. Modeling, monitoring, and validating green roof and green facade solutions with semantic city models using low cost sensors and open software infrastructures. Urban Science, 3(2):39, 2019. doi:https://doi.org/10.3390/urbansci3020039.

YAGA AS. Yaga dugpunkskalkulator, 2020. URL https: //www.yaga.no/dpkalkulator.php. 